\title{
A theoretical study on the reaction of ozone with aqueous iodide
}

Óscar Gálvez ${ }^{\mathrm{a}}$, M. Teresa Baeza-Romero ${ }^{\mathrm{b}}$, Mikel Sanz $^{\mathrm{c}}$ and Luis F. Pacios ${ }^{\mathrm{d}}$

\footnotetext{
${ }^{a}$ Departamento de Física Molecular, Instituto de Estructura de la Materia, IEM-CSIC, 28006 Madrid, Spain.

${ }^{\mathrm{b}}$ Escuela de Ingeniería Industrial, Universidad de Castilla-La Mancha, 45071, Toledo, Spain.

c Escuela de Ingeniería Industrial, Universidad de Castilla-La Mancha, 45071, Toledo, Spain. Now at Instituto de Química Física Rocasolano, IQFR-CSIC, 28006, Madrid, Spain.

d Unidad de Química, Departamento de Sistemas y Recursos Naturales, E.T.S.I. Montes, Universidad Politécnica de Madrid, 28040 Madrid, Spain.

Correspondence to O. Gálvez (Email: oscar.galvez@csic.es)
}

\section{Abstract}

Atmospheric iodine chemistry plays a key role in tropospheric ozone catalytic destruction, new particle formation, and as one of the possible sinks of gaseous polar elemental mercury. Moreover, it has been recently proposed that reaction of ozone with iodide on sea surface could be the major contributor to the chemical loss of atmospheric ozone. However, the mechanism of the reaction between aqueous iodide and ozone is not well known. The aim of this paper is to improve the understanding of such mechanism. In this paper, it is presented an $a b$ initio study of the reaction of aqueous iodide and ozone, evaluating thermodynamic data of the different reactions proposed in previous experimental studies. In addition, the structures, energetics and possible evolution of the key $1000^{-}$intermediate are discussed for the first time.

\section{Introduction}

Atmospheric iodine chemistry has received special attention in the last decades (see Saiz-Lopez, Plane et al. $2012^{1}$ and references therein), since it plays a relevant role in tropospheric ozone catalytic destruction ${ }^{2,3}$ and new particle formation. ${ }^{4}$ Moreover, in the polar atmosphere, iodine has also been suggested as one of the possible sinks of gaseous elemental mercury. ${ }^{5}$

Ozone is a key atmospheric molecule. In the stratosphere, it prevents us from the damaging short-wave ultraviolet rays. In the troposphere, ozone absorbs infrared radiation as a greenhouse gas, and it has adverse effects in air quality and public health (see e.g.: Arlene et al., $2015^{6}$ ). In the lower atmosphere, ozone is mainly produced over the continents (due to the oxidation of organic compounds during daytime in the presence of nitrogen oxides), and transported to the marine boundary layer where major destruction occurs, mainly by its own photolysis. However, the ozone loss calculated for all the known processes, excluding halogens, accounts for only about $50 \%$ of total loss. In this context, iodine has been proposed as the main contributor to halogen-mediated destruction of ozone. ${ }^{2}$

Up to date, biogenic sources such as marine macroalgae and phytoplacton have been assumed to be the main supplier of atmospheric iodine compounds, mainly $I_{2}$ and iodine-containing organic molecules. ${ }^{7}$ However, these sources cannot account for the total amount of gas-phase iodine oxide concentration observed. ${ }^{8,9}$ Recently, it has been proposed that the reaction of ozone with iodide on the sea surface could be the major contributor to the chemical loss of atmospheric ozone, and that it could also account for about $75 \%$ of the observed iodine oxide levels over tropical Atlantic Ocean. ${ }^{10}$

The reaction of aqueous iodide with ozone yields $I_{2}$ according to the following previously proposed basic mechanism (aqueous phase is assumed for reactants and products excepted where explicitly indicated): ${ }^{11-13}$

$$
\begin{array}{ll}
\mathrm{H}^{+}+\mathrm{I}^{-}+\mathrm{O}_{3} \rightarrow \mathrm{HOI}+\mathrm{O}_{2} & \mathrm{R} 1 \\
\mathrm{H}^{+}+\mathrm{HOI}+\mathrm{I}^{-} \leftrightarrows \mathrm{I}_{2}+\mathrm{H}_{2} \mathrm{O} & \mathrm{R} 2 \\
\mathrm{I}_{2} \leftrightarrows \mathrm{I}_{2}(\mathrm{~g}) & \mathrm{R} 3
\end{array}
$$

Recent studies have pointed that reaction R1 would occur in the air/water interface, ${ }^{14-16}$ where ${ }^{-}$concentration is enriched in relation to the bulk phase.$^{17,18} \mathrm{It}$ is worth to highlight that in fine sea salt aerosol particles the I concentration observed was about 2 and 4 orders of magnitude higher than in seawater, ${ }^{19-22}$ consequently it is expected that these reactions could happen into aerosols too, although there are no experimental studies up to date.

Apart from $\mathrm{I}_{2}(\mathrm{~g})$, a previous study revealed that $\mathrm{IO}(\mathrm{g})$ was also detected as a product of this reaction, although its release was about 100 times lower than $\mathrm{I}_{2}(\mathrm{~g}) .{ }^{13}$ In this work, it was proposed that the reaction progresses via an $1000^{-}$intermediate, in accord with the identification of an analogous $\mathrm{BrOOO}^{-}$intermediate in the reaction of $\mathrm{Br}^{-}$and $\mathrm{O}_{3}$ at the air/aerosol interface. ${ }^{23}$ Taken this into account, reaction $\mathrm{R} 1$ could be rewritten as:

$$
\begin{array}{ll}
\mathrm{I}^{-}+\mathrm{O}_{3} \rightarrow \mathrm{IOOO}^{-} & \mathrm{R} 4 \\
\mathrm{IOOO}^{-} \rightarrow \mathrm{IO}^{-}+\mathrm{O}_{2} & \mathrm{R} 5 \\
\mathrm{IO}^{-}+\mathrm{H}^{+} \leftrightarrows \mathrm{HOI} \quad(\mathrm{pKa}=10.8) & \mathrm{R} 6
\end{array}
$$


$\mathrm{IO}(\mathrm{g})$ was suggested as product resulting from the evolution of the $1000^{-}$intermediate by several step reactions, although no experimental confirmation of this mechanism was provided. ${ }^{13}$

More recently, it has been shown that $\mathrm{HOI}(\mathrm{g})$ is also emitted to the gas phase (reaction R7) in the reaction between iodide and ozone, even at much higher concentration than $\mathrm{I}_{2}(\mathrm{~g})$ (around 500 times more), therefore hypoiodous acid has been suggested to be the main carrier of iodine from oceans to the atmosphere. ${ }^{10,24}$

$$
\mathrm{HOI} \leftrightarrows \mathrm{HOI}(\mathrm{g})
$$

Furthermore, other experiments conducted on this reaction in aqueous microdroplets have recently revealed that oxidation of iodide by ozone leads to formation in the aqueous phase of different species such as $\mathrm{IO}_{3}{ }^{-}, \mathrm{IO}_{2}{ }^{-}$and $\mathrm{I}_{3}{ }^{-}$, with increasing concentration at higher ozone levels. ${ }^{25}$ In that work, a possible mechanism for the production of these species in the air/water interface was also suggested:

$$
\begin{array}{ll}
\mathrm{HOI}+\mathrm{O}_{3} \rightarrow \mathrm{IO}_{2}^{-}+\mathrm{O}_{2}+\mathrm{H}^{+} & \mathrm{R} 8 \\
\mathrm{IO}_{2}^{-}+\mathrm{O}_{3} \rightarrow \mathrm{IO}_{3}^{-}+\mathrm{O}_{2} & \mathrm{R} 9 \\
\mathrm{I}_{2}+\mathrm{I}^{-} \leftrightarrows \mathrm{I}_{3}^{-} & \mathrm{R} 10
\end{array}
$$

Nevertheless, there are no systematic kinetic and thermodynamic studies of reactions R1-R10. Such information is desirable to assess the validity of these proposed processes. In this regard, and aiming to gain insight into the mechanism of the reaction between aqueous iodide and ozone, we present here, for the first time, an ab initio study of reactions proposed in previous experimental works, paying special attention to their thermodynamic features. In addition, a first theoretical investigation about possible structures and evolution of the key $1000^{\circ}$ intermediate is also presented. As discussed below, the complexity of this system revealed by our ab initio study led us to consider the current report as a first piece of evidence on the chemical behavior of the $1000^{-}$intermediate on one side, and as a motivation for future theoretical and/or experimental works on the other side.

\section{Methods}

Quantum calculations on iodinated species were performed using a shape-consistent averaged relativistic effective potential (AREP) ${ }^{26}$ to replace the 46-electron core of the iodine atom. ${ }^{27}$ The AREP formalism has been shown to properly account for relativistic effects encapsulated in the core potential when used with flexible basis sets optimized for AREP operators. ${ }^{28}$ Valence-only aug-cc-pVTZ and aug-cc-pVQZ (i.e. aug-cc-pVXZ, X $=3$ and 4, respectively) basis sets were optimized for the iodine AREP ${ }^{29}$ following the procedure prescribed for generating correlated consistent basis sets for relativistic core potentials. ${ }^{30}$ Conventional aug-cc-pVXZ basis sets were employed for $\mathrm{H}$ and $\mathrm{O}$ atoms.

Optimized geometries and frequencies were obtained in second order Moller-Plesset calculations (MP2) with both $X=3,4$ correlated consistent basis sets checking in all cases that the geometries were true minima. Single point coupled cluster calculations, using single and double substitutions and including triple excitations, $\operatorname{CCSD}(T)$, energies were then computed at those optimized geometries, and complete basis set (CBS) extrapolation for these energies and aug-cc-pVXZ basis sets was determined with the two-point T-Z extrapolation formula: $E^{\text {corr }}(\infty)=E^{\text {corr }}(X)+$ $B /(X+1 / 2)^{3}, X=3$ and $4 .{ }^{31}$ Zero-point energies (ZPEs), enthalpy corrections and absolute entropies were determined at MP2/aug-cc-pVQZ frequencies calculations.

Additionally to gas phase calculations, two solvation models were also considered to treat all the species studied in the aqueous phase: (i) the polarizable continuum model $(\mathrm{PCM})^{32}$, which is one of the most widely used self-consistent reaction field models; and (ii) the COnductor-like Screening MOdel (COSMO) continuum solvation model which describes dielectric screening effects in solvents. ${ }^{33,}{ }^{34}$ The same set of calculations employed for the gas phase was used for both solvation models.

Spin-orbit (SO) corrections were obtained with the pseudopotential spin-orbit density functional theory (SODFT) method implemented in NWChem. ${ }^{35}$ This approach uses a relativistic two-component Hamiltonian that can be developed in either a basis set framework based on the zerothorder regular approximation, or a So pseudopotential framework. ${ }^{36}$ We used the latter procedure that requires the definition of an effective core potential and a matching SO potential, as that already constructed within the shape-consistent AREP formalism. ${ }^{26,}{ }^{28}$ After exploring different functionals customarily recommended for SODFT calculations ${ }^{37}$ (namely ACM, PBEO, and B3LYP) together with our AREP-SO operators for iodine in some benchmark molecules, ${ }^{38}$ we selected the B3LYP hybrid functional together with the aug-cc-pVQZ basis set for computing SO corrections in the gas phase of all the iodine species addressed in this work.

For the particular case of the ionic intermediate 1000, transition structures (TSs) between pairs of equilibrium geometries (see below) were also located by means of the QST2 (quadratic synchronous transit) approach ${ }^{39}$ from reactant and product input structures. These TS geometries were obtained at the MP2/AREP/aug-cc-pVQZ level of theory in both gas phase, and PCM solvated phase, and CCSD(T) energies (including CBS extrapolation) were then computed in single-point calculations at these MP2 QST2 geometries. Aimed to characterize the bonding nature of the $1000^{-}$intermediate, topological analysis of the electron density $\rho(\mathbf{r})$ of the three gas phase equilibrium structures was also conducted. $\rho(\mathbf{r})$ was obtained in all-electron MP2/TZVPP calculations and critical points of $\rho(\mathbf{r})$ were located and characterized according to the Atoms in Molecules (AIM) theory ${ }^{40,41}$ with the AIMAll package, ${ }^{42}$ which was also used to compute AIM atomic charges. In addition, atomic charges to fit the electrostatic potential according to the $\mathrm{CHelpG}$ scheme, ${ }^{43}$ and those corresponding to the natural population analysis (NPA) phase of natural bond orbital (NBO) ${ }^{44}$ 
calculations, were also obtained in both MP2/AREP/aug-cc-pVQZ and all-electron MP2/TZVPP calculations. An atomic radius $2.4 \AA$ for iodine obtained by multiplying its standard Van der Waals radius $2.0 \AA$ by the factor 1.2 used in CHelpG calculations for the Van der Waals radius of oxygen ${ }^{42}$ was employed to obtain $\mathrm{CHelpG}$ charges.

Geometries, frequencies, and energies regarding gas phase and PCM solvated phase as well as QST2, CHelpG and NBO calculations were performed with Gaussian $09 .{ }^{45}$ SODFT and COSMO calculations were carried out with NWChem $6.5 .{ }^{35}$

Thermodynamic data (enthalpies and Gibbs free energies of the studied reactions) were calculated using the following procedure: (i) first, geometries were optimized at the MP2/aug-cc-pVQZ level and ZPE, entropy and enthalpy corrections calculated at these structures; (ii) then single point CCSD $(T)$ /aug-cc-pVXZ $(X=T, Q)$ calculations were carried out at these geometries to include CBS correction; (iii) finally, SO corrections obtained as described above were added to total energies.

\section{Results and Discussion}

\subsection{Thermodynamic study of aqueous phase reactions of iodide with ozone.}

In order to assess the reliability of our methodology, especially that concerning evaluation of thermodynamic properties in aqueous solution, we used different approaches to compute the standard enthalpy of reaction R11:

$$
\mathrm{I}^{-}+\mathrm{O}_{3} \rightarrow \mathrm{IO}_{3}^{-}
$$

for which a reliable experimental value is available in aqueous solution. ${ }^{46}$ The reason to test just enthalpy instead of Gibbs free energy, is that inaccuracies in these energies are the main source of errors in $a b$ initio determination of Gibbs free energies of reactions, as entropies are usually rather well estimated. The results of this test are presented in Table 1, where it can be seen that both PCM and CPCM enthalpies provide reasonable estimates, and COSMO result is in excellent agreement with the experimental value. With the support provided by this result, PCM and COSMO schemes were chosen to compute Gibbs free energies of the aqueous reactions studied in this work.

Table 1. Computed and experimental standard enthalpy of reaction R11 in kcal.mol ${ }^{-1}$

\begin{tabular}{|c|c|c|c|c|c|}
\hline & PCM & CPCM & SMD & COSMO & Experimental $^{\mathrm{a}}$ \\
\hline$\Delta_{r} H^{0}$ & -67.42 & -67.03 & -79.21 & -69.89 & -69.81 \\
\hline
\end{tabular}

As mentioned in the introduction, the reaction between iodide and ozone in aqueous phase has been postulated to evolve by forming an $1000^{-}$intermediate. Different conformations for this species characterized as real minima in the potential energy surface were found in geometry optimizations and are depicted in Figure 1. Two different situations with three different conformers can be distinguished, one for which the geometry resembles an $\mathrm{I}^{-} \mathrm{O}_{3}$ adduct with a van der Waals-type interaction (conformation $\mathrm{C} 1$ in what follows), and another for which an $10^{\circ} \cdots \mathrm{O}_{2}$ geometry either in trans or cis arrangement (herein conformations $\mathrm{C} 2$ and $\mathrm{C} 3$, respectively) were found. A topological analysis on the nature of bonding for the interactions underlying those structures is presented below.

Considering the existence of these three conformers for the anionic $1000^{-}$intermediate, we postulate a mechanism in which reaction R4 initially progresses via formation of the adduct $\mathrm{I}^{-} \cdots \mathrm{O}_{3}(\mathrm{C} 1)$, which then undergoes an internal restructuration to yield an $10^{-} \cdots \mathrm{O}_{2}$ conformations, $\mathrm{C2}$ (R12a) or C3 (R12b), which they could also be in equilibrium between them (R12c):

$$
\begin{array}{ll}
\mathrm{I}^{-}+\mathrm{O}_{3} \rightarrow 1000^{\circ}(\mathrm{C} 1) & \mathrm{R} 4 \mathrm{~b} \\
1000^{-}(\mathrm{C} 1) \rightarrow 1000^{-}(\mathrm{C} 2) & \mathrm{R} 12 \mathrm{a} \\
1000^{-}(\mathrm{C} 1) \rightarrow 1000^{-}(\mathrm{C} 3) & \mathrm{R} 12 \mathrm{~b} \\
1000^{-}(\mathrm{C} 2) \leftrightarrows 1000^{-}(\mathrm{C} 3) & \mathrm{R} 12 \mathrm{c}
\end{array}
$$

Thermodynamic data calculated for the previous reactions together with other reactions that have been proposed in previous experimental studies are summarized in Table 2. The initial reaction between iodide and ozone to give $1000^{-}$(C1) presents a large positive Gibbs free energy (approx. $20 \mathrm{kcal} \mathrm{mol}^{-1}$ ), while small negative values are obtained in the intramolecular conversion from $\mathrm{C} 1$ to $\mathrm{C} 2$ conformation or even to $\mathrm{C} 3$. These results suggest that after $\mathrm{I}^{-} \cdots \mathrm{O}_{3}$ complex formation it is expect a spontaneous evolution towards the $10^{-} \cdots \mathrm{O}_{2}$ structure, which also shows a much larger negative free energy for the final release of $\mathrm{IO}^{-}$in the aqueous phase (approx. $-42 \mathrm{kcal} \mathrm{mol}^{-1}$, reaction R5). The $\Delta_{\mathrm{r}} \mathrm{G}$ for the global reaction $\mathrm{I}^{-}+\mathrm{O}_{3}(\mathrm{~g}) \rightarrow$ $10^{-}+\mathrm{O}_{2}$ is finally a large negative value around $-25 \mathrm{kcal}^{\mathrm{mol}}{ }^{-1}$, even larger than the analogous value for the reaction with bromine, around $-17 \mathrm{kcal}^{-\mathrm{mol}^{-}}$ 
${ }^{1.47}$ In consequence, it is expected that the first step of this reaction (R4b) to be thermodynamically limited if there is not an extra source of energy, but once $1000^{-}(\mathrm{C} 1)$ is formed the process is expected to be very fast. It has been proposed before that $\mathrm{I}^{-}+\mathrm{O}_{3}$ reactions happen mainly in the water interface ${ }^{25}$ which is in line with these results, since the extra energy required for $\mathrm{C} 1$ formation could be supplied by the kinetic energy of ozone in its uptake to water in the interface. ${ }^{48}$ Moreover, it is expected that other sources of energy such as light or temperature could activate this process, too.

Previous experimental studies about the effect of temperature into the rate coefficient of this reaction present contradictory results. In fact, while Magi el al. ${ }^{49}$ give a positive value of $17 \pm 7 \mathrm{kcal}^{\mathrm{mol}}{ }^{-1}$ for the activation energy that would be in line what it is observed in this work, other studies indicate a null or negative activation energy. ${ }^{24}$ However, we need to take into account that different experimental techniques and different species were monitored in those studies. While in the first study ozone was monitored, in the second one final products, $\mathrm{HIO}$ and $\mathrm{I}_{2}$, were measured. Further experimental and theoretical research that includes determination of rate coefficients in function of temperature would be desirable to confirm whether these reactions are barrierless or not.

Once $1000^{-}$complex ( $\mathrm{C} 2$ or $\mathrm{C} 3$ conformers) is formed, in addition to formation of $\mathrm{IO}^{-}$and $\mathrm{O}_{2}(\mathrm{~g})$, it could yield $\mathrm{IO}(\mathrm{g})$ and $\mathrm{O}_{2}^{-}$anion by the following reactions:

$$
\begin{array}{ll}
\mathrm{IOOO} \rightarrow \mathrm{IO}+\mathrm{O}_{2}^{-} & \mathrm{R} 5 \mathrm{C} \\
\mathrm{IO} \leftrightarrows \mathrm{IO}(\mathrm{g}) & \mathrm{R} 13
\end{array}
$$

which could be a possible pathway for $\mathrm{IO}(\mathrm{g})$ formation, product observed in previous experiments. ${ }^{13}$ This possible pathway is further discussed in next section.

Additionally, $10^{-}$could be formed in R5a or R5b:

$$
\begin{array}{lll}
1000^{-}(\mathrm{C} 2) \rightarrow 10^{-}+\mathrm{O}_{2} & \mathrm{R} 5 \mathrm{a} \\
1000^{-}(\mathrm{C} 3) \rightarrow 10^{-}+\mathrm{O}_{2} & \mathrm{R} 5 \mathrm{~b}
\end{array}
$$

$1 \mathrm{O}^{-}$is the conjugate base of the weak hypoiodous acid $(\mathrm{HOI})$, which is expected to be mainly in its protonated form at $\mathrm{pH}$ typical of sea water $\left(\mathrm{pH}_{\text {OCEAN }}\right.$ $\approx 8) .{ }^{10}$ Our computed value for Gibbs free energy of this reaction shows a fair agreement with the experimental value obtained from its $\mathrm{pK}_{\mathrm{a}}{ }^{13} \mathrm{HOI}$ could escape from the aqueous phase according to reaction R7, resulting in a slightly endergonic process, in nice agreement with the experimental value (see Table 2). However, aqueous HOI could further react with more iodide (R2) and/or dissolved ozone (R8) to generate new species being both

\begin{tabular}{|c|c|c|c|c|}
\hline \multirow{2}{*}{ ID } & \multirow{2}{*}{ Reaction } & \multicolumn{3}{|c|}{$\Delta_{\mathrm{r}} \mathrm{G}$} \\
\hline & & PCM & COSMO & Exp. \\
\hline R1 & $\mathrm{H}^{+}+\mathrm{I}^{-}+\mathrm{O}_{3} \rightarrow \mathrm{HOI}+\mathrm{O}_{2}$ & -44.75 & -42.54 & \\
\hline R2 & $\mathrm{HOI}+\mathrm{I}^{-}+\mathrm{H}^{+} \rightarrow \mathrm{I}_{2}+\mathrm{H}_{2} \mathrm{O}$ & -28.92 & -28.71 & \\
\hline R3 & $\mathrm{I}_{2} \leftrightarrows \mathrm{I}_{2}(\mathrm{~g})$ & 1.04 & 1.68 & $0.66^{\mathrm{a}}$ \\
\hline R4a & $\mathrm{I}^{-}+\mathrm{O}_{3}(\mathrm{~g}) \rightarrow \mathrm{IOOO}^{\circ}(\mathrm{C} 1)$ & 21.18 & 19.07 & \\
\hline R4b & $\mathrm{I}^{-}+\mathrm{O}_{3} \rightarrow 1000^{-}(\mathrm{C} 1)$ & 21.35 & 20.74 & \\
\hline R5a & $1000^{-}(\mathrm{C} 2) \rightarrow 10^{-}+\mathrm{O}_{2}$ & -42.00 & -42.71 & \\
\hline R5b & $1000^{-}(\mathrm{C} 3) \rightarrow 10^{-}+\mathrm{O}_{2}$ & -48.72 & -44.47 & \\
\hline R5c & $1000^{-}(\mathrm{C} 3) \rightarrow \mathrm{IO}+\mathrm{O}_{2}^{-}$ & -13.35 & -9.10 & \\
\hline R6 & $\mathrm{IO}^{-}+\mathrm{H}^{+} \leftrightarrows \mathrm{HOI}$ & -19.13 & -17.08 & $-15.01^{b}$ \\
\hline R7 & $\mathrm{HOI} \leftrightarrows \mathrm{HOI}(\mathrm{g})$ & 3.09 & 4.90 & $3.10^{c}$ \\
\hline R8 & $\mathrm{HOI}+\mathrm{O}_{3} \rightarrow \mathrm{IO}_{2}^{-}+\mathrm{O}_{2}+\mathrm{H}^{+}$ & -23.30 & -25.21 & \\
\hline R9 & $1 \mathrm{O}_{2}^{-}+\mathrm{O}_{3} \rightarrow 1 \mathrm{O}_{3}^{-}+\mathrm{O}_{2}$ & -82.15 & -80.90 & \\
\hline R10 & $\mathrm{I}_{2}+\mathrm{I}^{-} \leftrightarrows \mathrm{I}_{3}^{-}$ & 16.97 & 15.72 & $-3.90^{d}$ \\
\hline R11 & $\mathrm{I}^{-}+\mathrm{O}_{3} \rightarrow \mathrm{IO}_{3}^{-}$ & -59.60 & -61.69 & \\
\hline R12a & $1000^{-}(\mathrm{C} 1) \rightarrow \mathrm{IOOO}^{-}(\mathrm{C} 2)$ & -4.98 & -3.50 & \\
\hline R12b & $1000^{-}(\mathrm{C} 1) \rightarrow \mathrm{IOOO}^{-}(\mathrm{C} 3)$ & 1.74 & -1.73 & \\
\hline R12c & $1000^{-}(\mathrm{C} 2) \leftrightarrows 1000^{-}(\mathrm{C} 3)$ & 6.72 & 1.76 & \\
\hline R13 & $\mathrm{IO} \leftrightarrows \mathrm{IO}(\mathrm{g})$ & 2.37 & 6.23 & \\
\hline R14 & $\mathrm{IO}_{2}^{-}+\mathrm{H}^{+} \leftrightarrows \mathrm{HIO}_{2}$ & -12.88 & -11.11 & \\
\hline R15 & $\mathrm{HOI}+2 \mathrm{O}_{3} \rightarrow \mathrm{IO}_{3}^{-}+2 \mathrm{O}_{2}+\mathrm{H}^{+}$ & -105.4 & -106.1 & \\
\hline R16 & $10^{-}+2 \mathrm{O}_{3} \rightarrow 1 \mathrm{O}_{3}^{-}+2 \mathrm{O}_{2}$ & -124.5 & -123.2 & \\
\hline R17 & $\mathrm{IO}_{3}^{-}+5 \mathrm{I}^{-}+6 \mathrm{H}^{+} \rightarrow 3 \mathrm{I}_{2}+3 \mathrm{H}_{2} \mathrm{O}$ & -70.82 & -65.11 & \\
\hline
\end{tabular}
processes predicted spontaneous in our study. Consequently, and in agreement with experimental findings, the $\mathrm{HOI}(\mathrm{g})$ concentration is expected to be larger than $\mathrm{I}_{2}(\mathrm{~g})$ concentration at low $\mathrm{I}^{-}$and $\mathrm{O}_{3}$ concentration. ${ }^{10}$

Table 2. Calculated and estimated Gibbs free energy of reactions studied in kcal.mol ${ }^{-1}$.

${ }^{a}$ Experimental value obtained from $\mathrm{K}_{\mathrm{eq}}=0.33$, Ref. ${ }^{50}$

${ }^{b}$ Experimental value obtained from $\mathrm{pK}_{\mathrm{a}}(\mathrm{HOI})=11.05$ in Ref. ${ }^{51}$

${ }^{\mathrm{C}}$ Experimental value obtained from $\mathrm{K}_{\mathrm{eq}}=5.34 \times 10^{-3}$, Ref. $^{52}$

${ }^{\mathrm{d}}$ Experimental value obtained from $\mathrm{K}_{\text {eq }}=721$, Ref. ${ }^{53}$. 
The reaction of $\mathrm{HOI}$ with iodide is predicted to be a very exergonic process that would produce the spontaneous formation of $\mathrm{I}_{2}(\mathrm{aq})$, which in turn it could be also released to the gas phase (R3). Nevertheless, dissolved $I_{2}$ could additionally react with more iodide to produce $I_{3}{ }^{-}$anions (R10). In this case, our calculated value is far from the experimental one, which predicts formation of this anion as a favorable process (see Table 2). Considering that the estimates for the values of other reactions involving $\mathrm{I}^{-}$and $\mathrm{I}_{2}$ are in good agreement with experiment (e.g. R3 and R11), we suspect that our calculated values for the $\mathrm{I}_{3}{ }^{-}$anion in the aqueous phase should be the main reason for this discrepancy. Moreover, previous results obtained by our group using a similar methodology to test different properties of $\mathrm{I}_{3}{ }^{-}$in the gas phase yielded a nice agreement with experimental data. ${ }^{29}$ Consequently, we believe that the approximations involved in usual solvation models employed in quantum calculations, such as those used in this work, are not adequate for the particular case of this peculiar anionic molecule. Given that $\mathrm{I}_{3}{ }^{-}$is a highly polarizable molecule since it contains three iodine atoms, it can be proposed that continuum approximations to treat the solvent could not describe properly interactions with water molecules. The linear voluminous structure of this anion would suffer significant variations in the aqueous environment making rather difficult to treat theoretically, as it is known that the potential energy surface of $\mathrm{I}_{3}{ }^{-}$in water is fairly flat. ${ }^{54,55}$

Continuing with the discussion of the different pathways for the reaction of iodide with ozone depending on dissolved ozone concentration, if the concentration is high enough, $\mathrm{HOI}$ can be further oxidized and form iodite or iodate species following reactions R8 and R9. From a thermodynamically point of view, both processes are highly favored, especially the transformation of iodite to iodate, which could explain that iodate is the final species that accumulates onto aerosols, and iodite is uniquely observed as a transient species. ${ }^{25}$ R15-R17 reactions summarize the processes indicated above.

\subsection{Nature of bonding in the intermediate ion 1000}

As mentioned above, three stable (true minima) structures were found for the intermediate ion $1000^{-}$with geometries shown in Fig. 1 and Table 3. Except for minor differences regarding some geometry parameters that are below analyzed, these structures are qualitatively similar in the gas phase and in the two solvation models, PCM and COSMO, considered here. Both approaches agree in predicting $\mathrm{C} 2$ as the lowest lying structure, but $\mathrm{PCM}$ places $\mathrm{C} 1$ at $\sim 5 \mathrm{kcal}^{\mathrm{mol}}{ }^{-1}$ and then $\mathrm{C} 3$ at $\sim 7 \mathrm{kcal}^{\mathrm{mol}}{ }^{-1}$ above $\mathrm{C} 2$, whereas $\mathrm{COSMO}$ modifies this energetic order predicting $\mathrm{C} 3$ as the structure with minimum energy after $\mathrm{C} 2$ with only $\sim 2 \mathrm{kcal} \mathrm{mol}^{-1}$ more, and then $\mathrm{C} 1$ at $3.5 \mathrm{kcal}^{\mathrm{mol}}{ }^{-1}$ above $\mathrm{C} 2$ (see Table 2). It must be noted that previous reports of $a b$ initio calculations on the BrOOO intermediate arising from reactions of ozone with bromide either found only one conformer (with structure similar to our (1 geometry of $\left.1000^{\circ}\right),{ }^{56,57}$ or were unable to find theoretical evidence on the existence of these species, in this case probably due to the level of theory employed. ${ }^{47}$ With the objective to characterize the nature of bonding, as well as the charge balance in these structures, we gather some topological descriptors of bond critical points (BCPs) of $\rho(r)$ in Table 4, together with atomic charges computed with three different population analyses, namely NPA, CHelpG, and AIM, in Table 5. Since the topology of $\rho(r)$ and atomic charges provide information on the electron distribution associated to the nature of bonding in $1000^{-}$, these properties are addressed only for geometries in the gas phase.

Table 3. MP2/AREP/aug-cc-pVQZ optimized geometries of the three equilibrium structures of the intermediate ion $1000^{-}$in gas and solvated phases obtained in PCM and COSMO calculations

\begin{tabular}{|c|c|c|c|}
\hline Parameter & Gas & PCM & COSMO \\
\hline \multicolumn{4}{|c|}{ C1 geometry } \\
\hline$r(I 1-02)$ & 2.754 & 2.720 & 2.704 \\
\hline$r(\mathrm{O} 2-03)$ & 1.374 & 1.371 & 1.362 \\
\hline$r(03-04)$ & 1.282 & 1.286 & 1.279 \\
\hline$a(\mid 1-02-03)$ & 100.4 & 98.4 & 100.8 \\
\hline$a(02-03-04)$ & 114.2 & 113.3 & 113.9 \\
\hline$d(\mathrm{I} 1-\mathrm{O} 2-\mathrm{O} 3-\mathrm{O} 4)$ & 69.6 & 65.9 & 69.9 \\
\hline \multicolumn{4}{|c|}{ C2 geometry (trans-) } \\
\hline$r(11-02)$ & 1.908 & 1.927 & 1.927 \\
\hline$r(\mathrm{O} 2-\mathrm{O} 3)$ & 1.950 & 1.888 & 1.936 \\
\hline$r(\mathrm{O} 3-04)$ & 1.274 & 1.275 & 1.274 \\
\hline$a(11-02-03)$ & 99.3 & 99.6 & 97.3 \\
\hline$a(02-03-04)$ & 111.4 & 111.0 & 113.1 \\
\hline$d(\mathrm{I} 1-\mathrm{O} 2-\mathrm{O} 3-\mathrm{O} 4)$ & 180.0 & 180.0 & 180.0 \\
\hline \multicolumn{4}{|c|}{ C3 geometry (cis-) } \\
\hline$r(\mid 1-02)$ & 1.856 & 1.863 & 1.870 \\
\hline$r(02-03)$ & 2.104 & 2.082 & 2.082 \\
\hline$r(03-04)$ & 1.441 & 1.449 & 1.425 \\
\hline$r(04-I 1)$ & 2.411 & 2.429 & 2.446 \\
\hline$a(\mid 1-02-03)$ & 91.3 & 92.8 & 92.9 \\
\hline$a(\mathrm{O} 2-03-04)$ & 99.0 & 98.6 & 99.1 \\
\hline$a(03-04-11)$ & 91.31 & 91.5 & 91.7 \\
\hline$a(04-11-02)$ & 78.45 & 77.1 & 76.2 \\
\hline$d(\mid 11-02-03-04)$ & 0.0 & 0.0 & 0.0 \\
\hline
\end{tabular}


Atom numbering and geometry labels refer to Fig. 1. Bond lengths $r$ in $\AA$, bond angles $a$ and dihedrals $d$ in degrees.

Table 4. Topological descriptors of critical points of the all-electron MP2/TZVPP electron density computed at gas phase MP2/AREP/aug-cc-pVQZ optimized geometries of three equilibrium structures of the intermediate ion $1000^{-}$

\begin{tabular}{|c|c|c|c|c|c|c|}
\hline Bond & $\rho_{\mathrm{c}}$ & $\nabla^{2} \rho_{\mathrm{c}}$ & $\varepsilon$ & $G_{\mathrm{c}}$ & $V_{c}$ & $H_{\mathrm{C}}$ \\
\hline \multicolumn{7}{|c|}{ C1 geometry } \\
\hline 11-02 & 0.0316 & 0.0779 & 0.1503 & 0.2076 & -0.2205 & -0.0129 \\
\hline $\mathrm{O} 2-\mathrm{O} 3$ & 0.3371 & 0.1529 & 0.0438 & 0.3251 & -0.6119 & -0.2868 \\
\hline O3-O4 & 0.4372 & -0.3229 & 0.0607 & 0.4113 & -0.9034 & -0.4921 \\
\hline \multicolumn{7}{|c|}{ C2 geometry (trans-) } \\
\hline |1-02 & 0.1511 & 0.3089 & 0.0279 & 0.1606 & -0.2441 & -0.0835 \\
\hline O2-03 & 0.0805 & 0.2645 & 0.1857 & 0.0732 & -0.0803 & -0.0071 \\
\hline O3-O4 & 0.4424 & -0.3461 & 0.0407 & 0.4200 & -0.9266 & -0.5066 \\
\hline \multicolumn{7}{|c|}{ C3 geometry (cis-) } \\
\hline 11-02 & 0.1672 & 0.4385 & 0.0041 & 0.2062 & -0.3028 & -0.0966 \\
\hline $\mathrm{O} 2-\mathrm{O} 3$ & 0.0571 & 0.1848 & 0.1196 & 0.0494 & -0.0525 & -0.0031 \\
\hline O3-O4 & 0.2749 & 0.2835 & 0.0010 & 0.2537 & -0.4364 & -0.1827 \\
\hline O4-I1 & 0.0602 & 0.1043 & 0.2450 & 0.0398 & -0.0536 & -0.0138 \\
\hline RCP & 0.0272 & 0.1457 & & 0.0329 & -0.0294 & +0.0035 \\
\hline
\end{tabular}

Atom numbering and geometry labels refer to Fig. 1. All values (atomic units) correspond to $(3,-1)$ bond critical points except RCP that is the $(3,+1)$ ring critical point in the $\mathrm{C} 3$ geometry. Topological descriptors are the following variables computed at the critical points: electron density $\rho_{\mathrm{C}}$, Laplacian of the electron density $\nabla^{2} \rho_{C}$, ellipticity $\varepsilon$, kinetic energy density $G_{C}$, potential energy density $V_{\mathrm{c}}$, and total energy density $H_{\mathrm{C}}=G_{\mathrm{C}}+V_{\mathrm{C}}$

The main feature of $1000^{-}$structures is that $\mathrm{C} 1$ can be regarded as a $\left(1 \cdots \mathrm{O}_{3}\right)^{-}$arrangement that would directly arise from reaction of iodide with ozone, whereas both $\mathrm{C} 2$ and $\mathrm{C} 3$ structures might be viewed as trans and cis isomers of a $\left(\mathrm{IO}^{-\cdots} \mathrm{O}_{2}\right)^{-}$arrangement, respectively, being the trans isomer more stable. To analyze these geometries, it is helpful to take into account the following results obtained at same levels of theory for the components of those two arrangements (they are given in the following order: gas, PCM and COSMO). Bond lengths ( $(\AA)$ in $10^{\circ}: 1.899,1.918,1.919$. Ibid. in $\mathrm{O}_{2}: 1.216,1.216,1.216$. Ibid. in $\mathrm{O}_{3}: 1.275,1.274,1.272$ and bond angle $\left(^{\circ}\right)$ in $\mathrm{O}_{3}: 116.9,116.7$, and 116.7 . In what follows, we discuss $\mathrm{C} 1, \mathrm{C} 2$, and C3 structures in turn addressing together geometries (Table 3), topological properties of BCPs (Table 4) and atomic charges (Table 5).

Table 5 All-electron MP2/TZVPP atomic charges computed at gas phase MP2/AREP/aug-cc-pVQZ optimized geometries of three equilibrium structures of the intermediate ion 1000

\begin{tabular}{|c|c|c|c|}
\hline Atom & NPA & CHelpG & AIM \\
\hline \multicolumn{4}{|c|}{ C1 geometry } \\
\hline I1 & -0.600 & -0.668 & -0.572 \\
\hline $\mathrm{O} 2$ & -0.345 & -0.224 & -0.335 \\
\hline 03 & +0.160 & +0.079 & +0.133 \\
\hline $\mathrm{O} 4$ & -0.215 & -0.187 & -0.226 \\
\hline \multicolumn{4}{|c|}{ C2 geometry } \\
\hline I1 & +0.260 & -0.295 & +0.289 \\
\hline $\mathrm{O} 2$ & -0.836 & -0.312 & -0.859 \\
\hline 03 & -0.196 & -0.108 & -0.172 \\
\hline $\mathrm{O} 4$ & -0.228 & -0.285 & -0.258 \\
\hline \multicolumn{4}{|c|}{ C3 geometry } \\
\hline 11 & +0.607 & -0.081 & +0.630 \\
\hline $\mathrm{O} 2$ & -0.838 & -0.344 & -0.869 \\
\hline O3 & -0.304 & -0.280 & -0.311 \\
\hline $\mathrm{O} 4$ & -0.465 & -0.295 & -0.450 \\
\hline
\end{tabular}

Atom numbering and geometry labels refer to Fig. 1 .

All values in atomic units. 
In $\mathrm{C} 1$, the long $11-02$ distance $\sim 2.7 \AA$, and $02-03$ and 03-04 distances 1.37 and $1.28 \AA$ A respectively, similar to that of ozone $(1.27 \AA$ ), clearly suggest that this structure could be considered an $1 \cdots \mathrm{O}_{3}$ aggregate, as mentioned before. The I1-O2 bond path shows topological properties indicative of a weak interaction: ${ }^{40,41}$ small values of the electron density $\left(\rho_{c}\right)$ and its positive Laplacian (local depletion of electron charge) at the BCP $\left(\nabla^{2} \rho_{c}\right)$, a relatively large ellipticity $(\varepsilon)$, and small values of kinetic $\left(G_{C}\right)$ and potential $\left(V_{c}\right)$ energy densities, which yield a very small (though still negative) total energy density $\left(H_{C}\right)$ at the BCP that hints at weak covalent features (Table 4$)$. On the contrary, the O3-O4 bond path shows typically covalent values of these descriptors: large $\rho_{c}$, large negative $\nabla^{2} \rho_{c}$ (local concentration of electron charge), small $\varepsilon$ (low anisotropy of the electron density at the BCP), and large energy densities $G_{C}, V_{c}$, and $H_{C}$ with values prototypical of strong covalent bonds. The interaction between 11 and 02 atoms produces an $02-$ O3 bond distance $\sim 1.37 \AA$, a bit longer than that of ozone $\left(1.27 \AA\right.$ ), and an 02-03-04 bong angle $\sim 114^{\circ}$ a bit closer than that of ozone $\left(117^{\circ}\right)$. While still exhibiting clearly covalent features, the topological descriptors of the $\mathrm{O} 2-\mathrm{O} 3$ bond path indicate a slightly weaker interaction when compared to those of the 03-O4 bond path. The basins path map (Fig. 1) of C1 structure reveals a clear separation between the atomic basin of iodine and those of oxygen atoms. Recall that in AIM theory, the nuclei are the attractors of the gradient vector field of $\rho(r)$, and that the region of space traversed by the trajectories terminating at a nucleus defines a basin. An "atom" in AIM theory is just defined by the union of an attractor (nucleus) and its basin, so that the space of a molecule can be unambiguously partitioned into $3 \mathrm{D}$ atomic basins. The dihedral angle $\sim 66-70^{\circ}$ gives rise to a sharp separation between the basins of iodine and the three oxygen atoms that lend further support to the " 1 - $\mathrm{O}_{3}$ " picture of this structure. Contrarily to what happens with structures $\mathrm{C} 2$ and $\mathrm{C} 3$ (Table 5), the three sets of atomic charges are also consistent in predicting a differentiated role for iodine, which bears most of the negative charge of this anionic intermediate.

In relation to the influence of the aqueous environment on C1 structure predicted by PCM and COSMO approaches, geometry data in Table 3 suggest minor changes with respect to the gas phase. Both methods agree in predicting for the solvated phase slightly shorter $11-02$ and $02-03$ distances, and a bit closer 02-03-04 bond angle than for the gas phase, while they differ in the changes predicted for 03-04 bond length, 11-02-03 bond angle and the dihedral angle. However, all these differences are so small that it could be stated that the aqueous environment has no significant effect on this $\mathrm{C} 1$ geometry, a feature also found for $\mathrm{C} 2$ and $\mathrm{C} 3$ conformations.

$\mathrm{C} 2$ is the most stable of the three 1000 equilibrium structures found. In this geometry, 11-02 and 03-04 are nearly equal to those of isolated $10^{-}$and $\mathrm{O}_{3}$ molecules, respectively, while the very long 02-03 distance 1.89-1.95 $\AA$ clearly indicates a weak bonding between 1102 and 0304 segments. Note that the 03-04 bond length does not resemble that of oxygen molecule, but rather it is essentially identical to that of ozone, as it happens in $\mathrm{C} 1$. Note additionally that $11-02-03$ and $02-03-04$ bond angles are not very different to those of the $\mathrm{C} 1$ geometry. However, the topological analysis of the electron density establishes a major difference between $\mathrm{C} 1$ and $\mathrm{C} 2$ structures with regard to the properties of oxygen atoms. In fact, while the 03-O4 bond path exhibits nearly identical features in $\mathrm{C} 2$ and $\mathrm{C} 1$ geometries (Table 4), the $02-03$ bond path in $\mathrm{C} 2$ shows values reminiscent of a weak interaction (small $\rho_{C}$, large $\varepsilon$, and so small values of $G_{C}, V_{C}$, and $H_{C}$ that they might barely make one think of a covalent bond), contrarily to what happens in $\mathrm{C} 1$ where this bond path may be regarded as conventionally covalent. The basins path maps exhibits the features expected for a plane molecule: tight arrangement of vector field lines in the proximity of the critical points with sharp separatrices between contiguous atomic basins.

In contrast with C1 results, atomic charges in C2 are inconsistently predicted by the three population analyses (Table 5). In spite of following completely different theoretical approaches, NPA and AIM methodologies closely agree in predicting a large negative charge on 02 atom and a positive charge on 11 atom. On the contrary, $\mathrm{CHelpG}$ charges (obtained under the condition to reproduce the electrostatic potential) place a similar negative value on those two atoms. The three sets of results agree, however, in predicting a total negative charge about -0.6e for the I1-02 segment, although it appears that the reproduction of the electrostatic potential poses a constraint in the form of shared contributions from both atoms. No significant differences are noticed in the 03-04 segment as the three sets of results agree in giving a net charge about $-0.4 \mathrm{e}$ for it.

The ring C3 structure is that presenting the greatest differences with respect to reference $10^{-}$and $\mathrm{O}_{3}$ molecules. The spatial constraints imposed by this cyclic structure give place to a short I1-02 bond distance, and particularly long 02-03 and 03-04 distances. In this case, and contrary to $\mathrm{C} 2$ conformation, both $11-02$ and 03-04 are now more similar to 10 and $\mathrm{O}_{2}^{-}$monomers (1.839 and $1.346 \AA$, respectively). Although it is not expected a bond between $\mathrm{I} 1$ and $\mathrm{O} 4$ given their interatomic distance longer than $2.4 \AA$, the topology of $\rho_{c}$ reveals not only that a bonding interaction does exist, but also that it shows covalent-like features, even more than the I1-02 bond in $\mathrm{C} 1$ structure. Except for the obvious difference arising from the presence of a ring critical point in $\mathrm{C} 3$, the basins path map of this geometry is equivalent to that of $\mathrm{C} 2$. Atomic charges show again the same discrepancy as in C2: similar NPA and AIM results predicting a large negative charge on O2, and a significant positive charge on 11 that nearly cancel each other, while $\mathrm{CHelpG}$ charges predict a nearly neutral iodine atom and a negative $\mathrm{O} 2$ atom with -0.34 e charge. Contrary to that found in $\mathrm{C2}$, now the three sets of atomic charges predict more negative values in the segment 03-04 (0.76e in NPA and AIM, and 0.57efor CHelpG) than I1-O2 in concordance with the bond distances analyzed above. This indicates that while the final product from the most stable conformer $\mathrm{C} 2$ is $\mathrm{HOI}$ while final products from $\mathrm{C} 3$ conformer would be $\mathrm{OO}+\mathrm{O}_{2}^{-}$. This is in agreement with the fact that experimentally it has been observed that the main gas phase product is $\mathrm{HIO}$, being $\mathrm{IO}$ a less important product. ${ }^{24}$

\subsection{Reaction path of changes in the conformations of $1000^{-}$}

In order to explore the formation process of $\mathrm{C} 1$ structure of $1000^{-}$intermediate from addition of $\mathrm{O}_{3}$ and $\mathrm{I}^{-}$, we obtained an energy curve at MP2/aug-cc-pVQZ calculations, including solvation effects with PCM, scanning the $\mathrm{I}^{\top} \cdots \mathrm{O} 2$ distance from as large values as $6 \AA\left(I^{-}+\mathrm{O}_{3}\right.$ as separated reactants), to a short $2 \AA$ distance (Fig. S1 in Supplementary Information). The main feature found is that $\mathrm{I}^{\top}$ and $\mathrm{O}_{3}$ attract each other until reaching a 
flat region between 2.6 and $3.8 \AA$ in which energy varies only $\sim 0.5 \mathrm{kcal}^{\mathrm{mol}}{ }^{-1}$. The $\Delta \mathrm{E}$ of formation of $\mathrm{C} 1$ with respect to the reactants obtained in MP2/aug-cc-pVQZ/PCM calculations is $-6.29 \mathrm{kcal} / \mathrm{mol}$ (C1 more stable in these $a b$ initio results). Analyzing Fig S1, the consequence is that formation of C1 takes place without transition state (TS) formation at the MP2 level of theory. However, the picture changes considerably when CCSD(T) energies are computed. Single point values (at MP2/QZ equilibrium geometries) with $\mathrm{TZ}$ and QZ basis sets give $\Delta \mathrm{E}=2.50$ and $3.62 \mathrm{kcal}^{\mathrm{mol}}{ }^{-1}$, respectively (C1 is now less stable than reactants). Moreover, inclusion of distinct corrections has the effect of increasing the differences. Thus, $\mathrm{CBS}$ correction places $\Delta \mathrm{E}$ at 4.35, ZPE increases it until 6.64 and finally, spin orbit effects give $\Delta \mathrm{E}=12.89$ (all values in kcal.mol ${ }^{-1}$ ). If Gibbs free energies are now considered, still larger differences are found, until reaching the value $21.35 \mathrm{kcal} / \mathrm{mol}$, which was that presented in Table 2.

Upon finding these results, we addressed the possibility that the $\operatorname{CSSD}(T)$ energy surface could be substantially different to that obtained with MP2 geometries. To this end and taking into account that use of QZ basis sets in $\operatorname{CSSD}(T)$ optimizations are computationally prohibitive, we obtained the structure for $\mathrm{C} 1$ in $\mathrm{CCSD}(\mathrm{T}) / \mathrm{TZ}$ calculations just trying to localize the minimum. This geometry happened to be similar to the MP2/QZ one (Fig. S2 in Supplementary Information). However, since small differences were observed in those geometries, we evaluated $\Delta \mathrm{E}$ of the reaction including only CBS correction obtaining a result of $2.44 \mathrm{kcal}^{\mathrm{mol}}{ }^{-1}$, close to the value found at the MP2/aug-cc-pVQZ optimization (4.35 kcal.mol ${ }^{-1}$ : see above). In this case, the conformational space of the MP2 energy surface should be thus considered equivalent to that obtained at the CCSD(T) level of theory. According to these results, $\operatorname{CCSD}(\mathrm{T})$ would predict $\mathrm{C} 1$ formation to be an endothermic process, so that the existence of a TS should be considered in this case, and a full treatment to search for the geometry of the TS or alternatively, an energy curve scanning the I-O2 distance in a similar manner to that done to obtain Fig. S1 had to be carried out. Since $\operatorname{CCSD}(\mathrm{T})$ calculations for both possibilities are enormously costly (particularly the frequencies calculation needed to find the TS), such a study is beyond the scope of the current work, and it had to be considered in forthcoming research.

Conversion of $\mathrm{C} 1$ in either $\mathrm{C} 2$ or $\mathrm{C} 3$ is predicted to occur with only one TS in MP2/aug-cc-pVQZ/PCM calculations. Another TS is also found to join C2 and C3. To further explore these conversions, we run minimum energy paths from the TS joining C1 with C2 or C3 (see Fig. 2). Point labelled

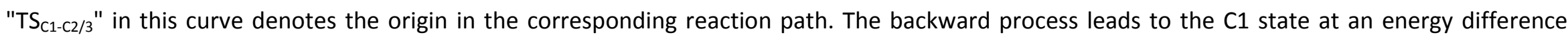
about $24 \mathrm{kcal}^{\mathrm{mol}}{ }^{-1}$ for the geometry displayed in Fig. 2 (this difference for MP2/aug-cc-pVQZ/PCM fully optimized structures of $\mathrm{C} 1$ is $26.42 \mathrm{kcal} . \mathrm{mol}^{-1}$ ). The curve for the forward process reveals more features. For instance, it shows a first plateau (labelled TS' in Fig. 2) which corresponds to a geometry similar to that found for the TS joining C2 with C3 (also shown in Fig. 2, TS $\mathrm{C}_{\mathrm{C}-\mathrm{C} 3}$ ): for example the $01 \cdots 02$ distance is $1.801 \AA$ in $\mathrm{TS}^{\prime}$ and $1.891 \AA$ in $\mathrm{TS}_{\mathrm{C} 2-}$ с3. One might conjecture that going from $\mathrm{TS}_{\mathrm{C} 1-\mathrm{C} 2 / 3}$ one could pass through $\mathrm{TS}_{\mathrm{C2}-\mathrm{C3}}$ and there would then be a bifurcation point to reach either $\mathrm{C} 2$ or $\mathrm{C} 3$ structures. Following that curve and after a slight change of curvature, the final point is C3 structure (see Fig. 2) at an energy difference about 27 kcal.mol ${ }^{-1}$ (this difference for MP2/aug-cc-pVQZ/PCM fully optimized structures of C3 is $27.43 \mathrm{kcal}^{-\mathrm{mol}^{-1}}$ ). However, the picture on these conversions again changes drastically upon performing single point $\operatorname{CCSD}(\mathrm{T})$ calculations and including $C B S$, ZPE and SO corrections.

A $\Delta G$ diagram for minima in the formation and destruction of the $1000^{-}$conformers is sketched in Figure 3 . Since CCSD(T)/aug-CC-pVTZ/PCM geometries for those minima were similar to the equivalent MP2 geometries, we might consider that diagram is essentially correct. For example, the conversion of $\mathrm{C} 1$ to $\mathrm{C} 2$ yields a $\Delta \mathrm{G}$ of $-4.98 \mathrm{kcal}^{\mathrm{mol}} \mathrm{l}^{-1}$ using optimized MP2 geometries or $-3.04 \mathrm{kcal}^{\mathrm{mol}} \mathrm{l}^{-1}$ at $\mathrm{CCSD}(\mathrm{T})$ minima. The major differences arise from C3 conformation (see Fig. S2 in Supplementary Information), although the order and final energy values of the different conformers in the diagram are essentially similar. Nevertheless and as mentioned above, a detailed description including $\Delta \mathrm{G}$ values for the different TSs in this diagram would obviously need a complete $\operatorname{CSSD}(\mathrm{T})$ treatment, a computational task so demanding that it would require a specific work far beyond the scope of the first report on the problem being presented here. As observed in Fig. 3, after formation of the $\mathrm{C} 1$ structure needing around $20 \mathrm{kcal}^{\mathrm{mol}}{ }^{-1}$, this intermediate could progress to release of $\mathrm{IO}^{-}$and $\mathrm{O}_{2}$, or $\mathrm{IO}$ and $\mathrm{O}_{2}^{-}$in the aqueous phase without thermodynamic barrier. However, it is important to highlight that in the most energetically favorable case (release of $\mathrm{O}_{2}$ and $\mathrm{IO}^{-}$), our calculated values assume that $\mathrm{O}_{2}$ is generated in the most stable electronic configuration, namely $X^{3} \Sigma_{\text {g }}^{-}$, which would imply a change of spin-state from the singlet state of $1000^{-}$(produced by addition of the reactants in their most stable singlet states) to the triplet state of oxygen. As another possibility, an internal change of spin state of I000 intermediate from singlet to triplet $\left(1000^{-}\left({ }^{1} X\right) \rightarrow 1000^{-}\left({ }^{3} A\right)\right)$ could release $X^{3} \Sigma_{g}^{-} O_{2}$ as final product. To explore these possibilities, we performed optimizations at MP2/aug-cc-pVQZ/PCM calculations for the three conformers of $1000^{-}$in their triplet states (results shown in Figure S3 in Supplementary Information). The geometry of the conformers underwent different changes, yielding for example larger $10^{-\cdots} \mathrm{O}_{2}$ distances for $\mathrm{C} 2$ and C3 conformers, and a $02-03$ bond length close to the value in $\mathrm{X}^{3} \Sigma_{\mathrm{g}}{ }^{-} \mathrm{O}_{2}$ molecule $(1.216 \AA)$. In any case, the triplet states of these conformers are less stable than singlets: $3.33,15.93$ and $10.28 \mathrm{kcal}^{\mathrm{mol}}{ }^{-1}$ for $\mathrm{C} 1, \mathrm{C} 2$ and $\mathrm{C} 3$, respectively (these values include CBS, ZPE, SO and G corrections as described in Methods section). According to these results, the possible change of the spin state in the $1000^{-}$intermediate could occur in the $\mathrm{C} 1$ conformation since it would need only an energy about $3 \mathrm{kcal}^{\mathrm{mol}}{ }^{-1}$. We must stress again that a more exhaustive study accounting for treatment of electron correlation of triplet and singlet electronic states at very high levels of theory is needed in the future to further explore the hypersurface of 1000 .

As a general experimental finding, reactions which imply electronic spin changes are usually more hindered, ${ }^{58,59}$ so alternatively we can assume that the oxygen product could be released in ${ }^{1} \Delta_{\mathrm{g}}$ state, similarly to what occurs when aqueous solutions of $\mathrm{Cl}_{2}$ (or hypochlorite ion) and hydrogen peroxide are mixed ${ }^{60}$. For this case, pioneering works date back to 1927 detected the red glow accompanying the $\mathrm{OCl}^{-}+\mathrm{H}_{2} \mathrm{O}_{2}$ reaction, chemiluminescence which subsequent reports attributed to the transition of excited singlet oxygen molecules $\left({ }^{1} \Delta_{\mathrm{g}}\right)$ to ground triplet state. In our reaction, ${ }^{1} \Delta_{\mathrm{g}}$ oxygen and $1 \mathrm{OO}^{-}$could similarly be the main products released from $\mathrm{C} 2$ or $\mathrm{C} 3$ conformations of $1000^{-}$both in their ground singlet states. It is well known that excited oxygen is more reactive than the ground triplet state, so it could have an important role in the evolution of the present reaction, although radiation-less relaxation to the ground state from collisional interaction with solvent molecules could also occur. ${ }^{61}$ In any case, the destruction of $\mathrm{C} 2$ or $\mathrm{C} 3$ structures of $1000^{-}$via release of ${ }^{1} \Delta_{\mathrm{g}} \mathrm{O}_{2}+10^{-}$are predicted to be exergonic, with calculated Gibbs free energies -12.65 and $19.37 \mathrm{kcal}^{\mathrm{mol}} \mathrm{l}^{-1}$ from C2 and C3, respectively. These results are lower (in absolute value) than those for release of $X^{3} \Sigma_{\mathrm{g}}$ oxygen (-42.00 and -48.72 kcal.mol ${ }^{-1}$ from $\mathrm{C} 2$ and $\mathrm{C} 3$ respectively, see Table 2 ). 


\section{Conclusions}

An $a b$ initio study of the reaction of aqueous iodide and ozone, evaluating thermodynamic data of the different reactions proposed in previous experimental studies has been done for the first time. It has been shown that the reaction may progress through a key $1000^{-}$intermediate that presents three different conformers. The formation of this intermediate is the crucial stage in the global reaction, and it is thermodinamically limited and probably it is the rate-limiting step. Our first set of results presented in the current work point to the possibility that formation and destruction of this intermediate could involve different transition states even implying spin-crossing reactions. As other alternative, evolution of the $1000^{-}$intermediate could yield electronic excited products such as ${ }^{1} \Delta_{\mathrm{g}}$ oxygen. In any case, considering the intricacy of the changes between the possible structures of $1000^{-}$, our results should be viewed as a first piece of evidence that has revealed for the first time the complex reaction pathway involved in formation and destruction of a key intermediate in the reaction of iodide and ozone. A further research on this molecular system would need a treatment of electron correlation at $\operatorname{CCSD}(\mathrm{T})$ or equivalent very high levels of theory, a demanding computational task which is well beyond the scope of the work reported here. However, the calculations presented in this work are reliable enough to predict that, depending on the conformers of $1000^{-}$formed, the reaction could progress to formation of $\mathrm{IO}$ or $\mathrm{HOI}$ species. Further reaction with $\mathrm{I}^{-}$or $\mathrm{O}_{3}$ are thermodynamically favored, leading to formation of iodine, iodite or iodate. Experimental observations of different aqueous and gas phase products are in agreement with the mechanism proposed in this work.

\section{Acknowledgments}

O. G. acknowledges financial support from Ministerio de Ciencia e Innovación, "Ramón y Cajal" program. O.G., M.T.B.R and M.S. acknowledge financial support from Ministerio de Economía y Competitividad, projects CGL2013-48415-C2-1-R and CGL2013-48415-C2-2-R. L. F. P. acknowledges financial support from Ministry of Science, Project BIO2013-41403R.

\section{References}

1. A. Saiz-Lopez, J. M. C. Plane, A. R. Baker, L. J. Carpenter, R. von Glasow, J. C. Gómez Martín, G. McFiggans and R. W. Saunders, Chemical Reviews, 2012, 112, 1773-1804.

2. K. A. Read, A. S. Mahajan, L. J. Carpenter, M. J. Evans, B. V. E. Faria, D. E. Heard, J. R. Hopkins, J. D. Lee, S. J. Moller, A. C. Lewis, L. Mendes, J. B. McQuaid, H. Oetjen, A. Saiz-Lopez, M. J. Pilling and J. M. C. Plane, Nature, 2008, 453, 1232-1235.

3. A. Saiz-Lopez, A. S. Mahajan, R. A. Salmon, S. J.-B. Bauguitte, A. E. Jones, H. K. Roscoe and J. M. C. Plane, Science, 2007, 317, 348-351.

4. C. D. O'Dowd, J. L. Jimenez, R. Bahreini, R. C. Flagan, J. H. Seinfeld, K. Hämeri, L. Pirjola, M. Kulmala, S. G. Jennings and T. Hoffmann, Nature, 2002, 417, 632-636.

5. J. G. Calvert and S. E. Lindberg, Atmospheric Environment, 2004, 38, 5105-5116.

6. A. M. Fiore, V. Naik and E. M. Leibensperger, Journal of the Air \& Waste Management Association, 2015, 65, 645-685.

7. L. J. Carpenter, Chemical Reviews, 2003, 103, 4953-4962.

8. C. E. Jones, K. E. Hornsby, R. Sommariva, R. M. Dunk, R. von Glasow, G. McFiggans and L. J. Carpenter, Geophysical Research Letters, 2010, 37, L18804 DOI: 18810.11029/12010GL043990.

9. A. S. Mahajan, J. M. C. Plane, H. Oetjen, L. Mendes, R. W. Saunders, A. Saiz-Lopez, C. E. Jones, L. J. Carpenter and G. B. McFiggans, Atmos. Chem. Phys., 2010, 10, 4611-4624.

10. L. J. Carpenter, S. M. MacDonald, M. D. Shaw, R. Kumar, R. W. Saunders, R. Parthipan, J. Wilson and J. M. C. Plane, Nature Geosci, 2013, 6, 108-111.

11. J. A. Garland and H. Curtis, Journal of Geophysical Research: Oceans, 1981, 86, 3183-3186.

12. S. Hayase, A. Yabushita, M. Kawasaki, S. Enami, M. R. Hoffmann and A. J. Colussi, The Journal of Physical Chemistry A, 2010, 114, 6016-6021.

13. Y. Sakamoto, A. Yabushita, M. Kawasaki and S. Enami, The Journal of Physical Chemistry A, 2009, 113, 7707-7713.

14. S. Enami, C. D. Vecitis, J. Cheng, M. R. Hoffmann and A. J. Colussi, The Journal of Physical Chemistry A, 2007, 111, 8749-8752.

15. S. Enami, C. D. Vecitis, J. Cheng, M. R. Hoffmann and A. J. Colussi, The Journal of Physical Chemistry A, 2007, 111, $13032-13037$.

16. S. Enami, C. D. Vecitis, J. Cheng, M. R. Hoffmann and A. J. Colussi, Chemical Physics Letters, 2008, 455, 316-320.

17. J. Cheng, M. R. Hoffmann and A. J. Colussi, The Journal of Physical Chemistry B, 2008, 112, 7157-7161.

18. J. Cheng, C. D. Vecitis, M. R. Hoffmann and A. J. Colussi, The Journal of Physical Chemistry B, 2006, 110, 25598-25602.

19. R. A. Duce, J. T. Wasson, J. W. Winchester and F. Burns, Journal of Geophysical Research, 1963, 68, 3943-3947.

20. R. A. Duce, J. W. Winchester and T. W. Van Nahl, Journal of Geophysical Research, 1965, 70, 1775-1799.

21. C. S. Martens, J. J. Wesolowski, R. C. Harriss and R. Kaifer, Journal of Geophysical Research, 1973, 78, 8778-8792.

22. J. L. Moyers and R. A. Duce, Journal of Geophysical Research, 1972, 77, 5229-5238.

23. S. W. Hunt, M. Roeselová, W. Wang, L. M. Wingen, E. M. Knipping, D. J. Tobias, D. Dabdub and B. J. Finlayson-Pitts, The Journal of Physical Chemistry A, 2004, 108, 11559-11572.

24. S. M. MacDonald, J. C. Gómez Martín, R. Chance, S. Warriner, A. Saiz-Lopez, L. J. Carpenter and J. M. C. Plane, Atmos. Chem. Phys., 2014, 14, 5841-5852.

25. E. A. Pillar, M. I. Guzman and J. M. Rodriguez, Environmental Science \& Technology, 2013, 47, 10971-10979.

26. L. F. Pacios and P. A. Christiansen, The Journal of Chemical Physics, 1985, 82, 2664-2671.

27. L. A. LaJohn, P. A. Christiansen, R. B. Ross, T. Atashroo and W. C. Ermler, The Journal of Chemical Physics, 1987, 87, $2812-2824$.

28. W. C. Ermler, R. B. Ross and P. A. Christiansen, in Advances in Quantum Chemistry, ed. P.-O. Löwdin, Academic Press, 1988, vol. Volume 19, pp. 139-182. 
29. L. F. Pacios and O. Gálvez, Journal of Chemical Theory and Computation, 2010, 6, 1738-1752.

30. J. M. L. Martin and A. Sundermann, The Journal of Chemical Physics, 2001, 114, 3408-3420.

31. S. B. Huh and J. S. Lee, The Journal of Chemical Physics, 2003, 118, 3035-3042.

32. J. Tomasi, B. Mennucci and R. Cammi, Chemical Reviews, 2005, 105, 2999-3094.

33. A. Klamt and G. Schuurmann, Journal of the Chemical Society, Perkin Transactions 2, 1993, DOI: 10.1039/p29930000799, $799-805$.

34. D. M. York and M. Karplus, The Journal of Physical Chemistry A, 1999, 103, 11060-11079.

35. M. Valiev, E. J. Bylaska, N. Govind, K. Kowalski, T. P. Straatsma, H. J. J. Van Dam, D. Wang, J. Nieplocha, E. Apra, T. L. Windus and W. A. de Jong, Computer Physics Communications, 2010, 181, 1477-1489.

36. P. Nichols, N. Govind, E. J. Bylaska and W. A. de Jong, Journal of Chemical Theory and Computation, 2009, 5, 491-499.

37. J. Kim, H. Ihee and Y. S. Lee, The Journal of Chemical Physics, 2010, 133, 144309.

38. O. Galvez, J. C. Gomez Martin, P. C. Gomez, A. Saiz-Lopez and L. F. Pacios, Physical Chemistry Chemical Physics, $2013,15,15572-15583$.

39. C. Peng, P. Y. Ayala, H. B. Schlegel and M. J. Frisch, Journal of Computational Chemistry, 1996, 17, 49-56.

40. R. F. W. Bader, Atoms in Molecules: A Quantum Theory, Clarendon, Oxford, UK, 1990.

41. P. Popelier, Atoms in Molecules: An Introduction, Prentice-Hall, Harlow, UK, 2000.

42. T. A. Keith, AIMAII (Version 14.11.23), TK Gristmill Software.Overland Park, KS, USA, 2014.

43. C. M. Breneman and K. B. Wiberg, Journal of Computational Chemistry, 1990, 11, 361-373.

44. A. E. Reed, L. A. Curtiss and F. Weinhold, Chemical Reviews, 1988, 88, 899-926.

45. R. D. Gaussian 09, M. J. Frisch, G. W. Trucks, H. B. Schlegel, G. E. Scuseria, M. A. Robb, J. R. Cheeseman, G. Scalmani, V. Barone, B. Mennucci, G. A. Petersson, H. Nakatsuji, M. Caricato, X. Li, H. P. Hratchian, A. F. Izmaylov, J. Bloino, G. Zheng, J. L. Sonnenberg, M. Hada, M. Ehara, K. Toyota, R. Fukuda, J. Hasegawa, M. Ishida, T. Nakajima, Y. Honda, O. Kitao, H. Nakai, T. Vreven, J. A. Montgomery, J. E. Peralta, F. Ogliaro, M. Bearpark, J. J. Heyd, E. Brothers, K. N. Kudin, V. N. Staroverov, R. Kobayashi, J. Normand, K. Raghavachari, A. Rendell, J. C. Burant, S. S. Iyengar, J. Tomasi, M. Cossi, N. Rega, J. M. Millam, M. Klene, J. E. Knox, J. B. Cross, V. Bakken, C. Adamo, J. Jaramillo, R. Gomperts, R. E. Stratmann, O. Yazyev, A. J. Austin, R. Cammi, C. Pomelli, J. W. Ochterski, R. L. Martin, K. Morokuma, V. G. Zakrzewski, G. A. Voth, P. Salvador, J. J. Dannenberg, S. Dapprich, A. D. Daniels, Farkas, J. B. Foresman, J. V. Ortiz, J. Cioslowski and D. J. Fox, Gaussian, Inc., Wallingford CT, 2009.

46. R. C. West, M. J. Astle and W. H. Beyer, Handbook of Chemistry and Physics, Florida, 64th. Edition, $1983-1984$ edn., 1984.

47. S. Rayne and K. Forest, Computational and Theoretical Chemistry, 2014, 1031, 22-33.

48. J. Vieceli, M. Roeselová, N. Potter, L. X. Dang, B. C. Garrett and D. J. Tobias, The Journal of Physical Chemistry B, $2005,109,15876-15892$.

49. L. Magi, F. Schweitzer, C. Pallares, S. Cherif, P. Mirabel and C. George, The Journal of Physical Chemistry A, 1997, 101, 4943-4949.

50. D. A. Palmer, R. W. Ramette and R. E. Mesmer, Journal of Nuclear Materials, 1985, 130, 280-286.

51. I. M. Kolthoff and P. J. Elving, Treatise on analytical chemistry, Interscience Encyclopedia, New York, 1959.

52. C.-C. Lin, Journal of Inorganic and Nuclear Chemistry, 1981, 43, 3229-3238.

53. R. C. Troy, M. D. Kelley, J. C. Nagy and D. W. Margerum, Inorganic Chemistry, 1991, 30, 4838-4845.

54. H. Sato, F. Hirata and A. B. Myers, The Journal of Physical Chemistry A, 1998, 102, 2065-2071.

55. T. Koslowski and P. Vöhringer, Chemical Physics Letters, 2001, 342, 141-147.

56. S. Naumov and C. von Sonntag, Ozone: Science \& Engineering, 2008, 30, 339-343.

57. Q. Liu, L. M. Schurter, C. E. Muller, S. Aloisio, J. S. Francisco and D. W. Margerum, Inorganic Chemistry, 2001, 40, 4436-4442.

58. J. N. Harvey, Wiley Interdisciplinary Reviews: Computational Molecular Science, 2014, 4, 1-14.

59. M. Swart and M. Costas, Spin States in Biochemistry and Inorganic Chemistry: Influence on Structure and Reactivity, John Wiley \& Sons, Ltd, 2015.

60. L. C. R. Mallet, Acad. Sri. Paris., 1927, 185, 352.

61. L. A. Martinez, C. G. Martínez, B. B. Klopotek, J. Lang, A. Neuner, A. M. Braun and E. Oliveros, Journal of Photochemistry and Photobiology B: Biology, 2000, 58, 94-107. 

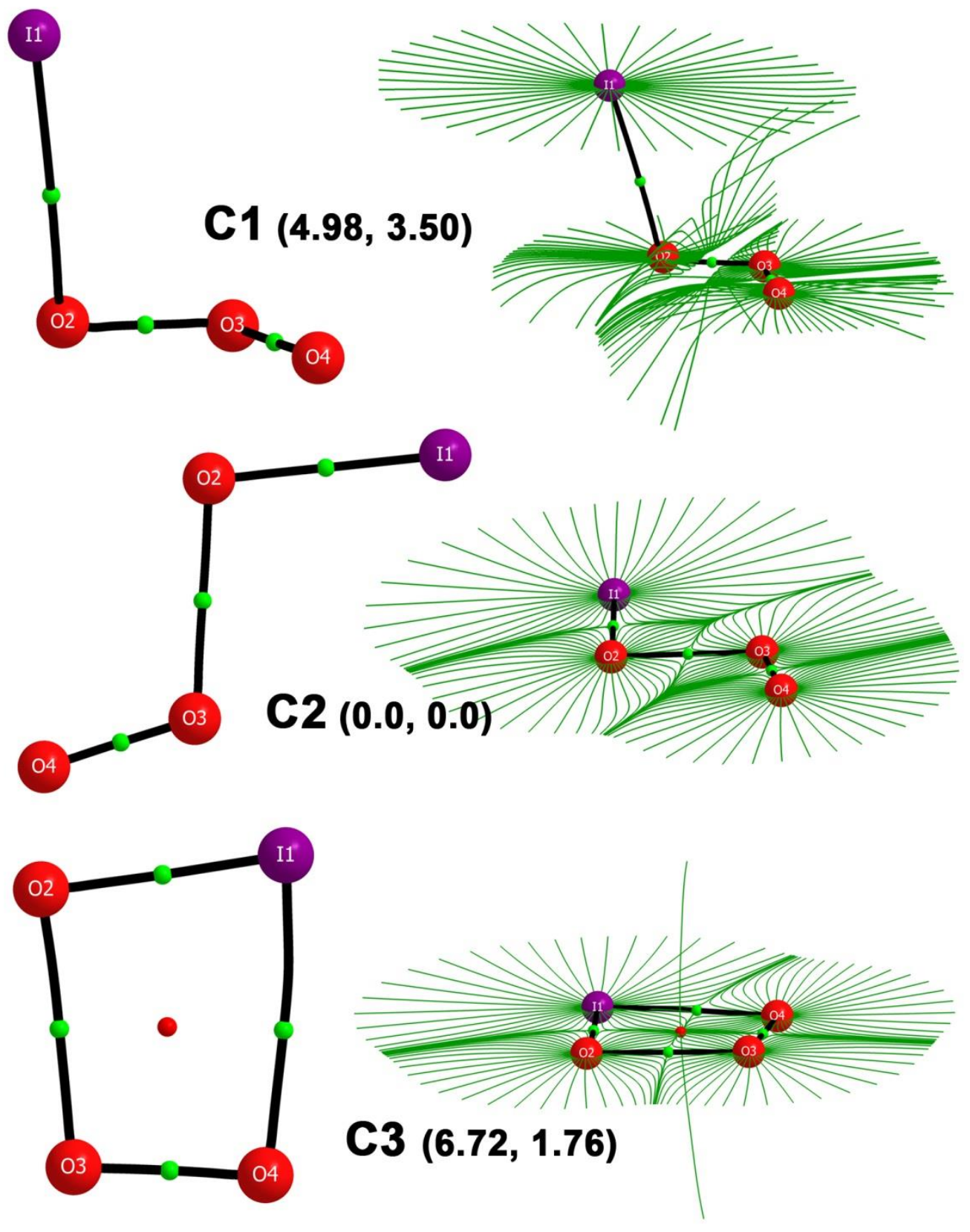

Figure 1. Three equilibrium structures of the intermediate ion $1000^{-}$showing the bond paths (thick black lines), bond critical points of the electron density $\rho(\mathbf{r})$ (green spheres), and the ring critical point in C3 geometry (small red sphere inside the cycle). Maps on the right display the gradient vector field lines of $\rho(r)$ that define the atomic basins. Values in parentheses are PCM and COSMO differences (kcal mol $\left.{ }^{-1}\right)$ in total $\operatorname{CCSD}(\mathrm{T})$ energies (that include SO, ZPE, CBD, and thermal corrections to Gibbs free energies) with respect to the lowest lying C2 structure. 


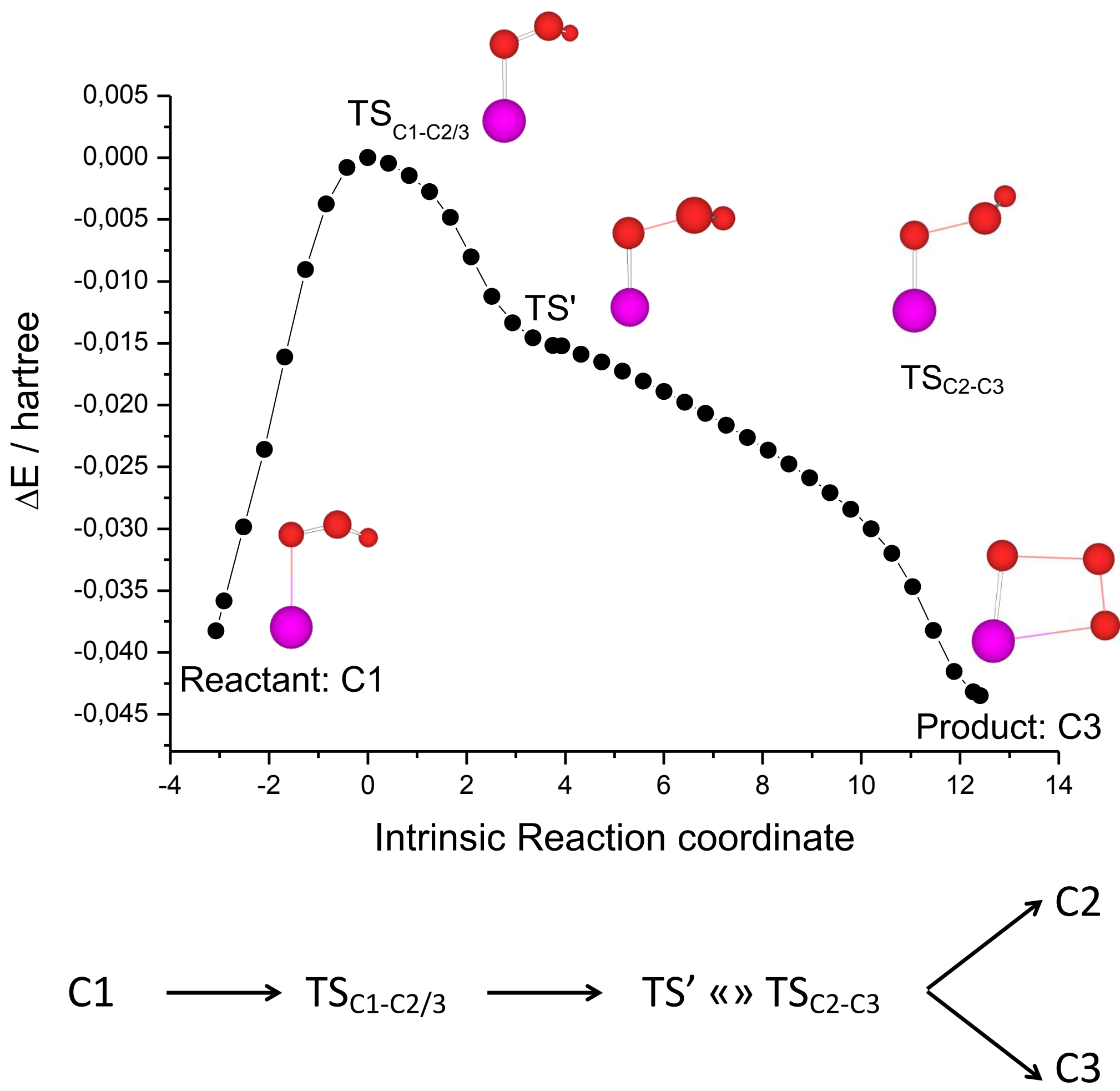

Figure 2. Reaction coordinate diagram for evolution from the TS joining $\mathrm{C} 1$ with either $\mathrm{C} 2$ or $\mathrm{C} 3$ along forward and backward reaction paths. Sketches of the structures corresponding to selected conformation are also included. A scheme of the whole process is included at the bottom of the diagram. 


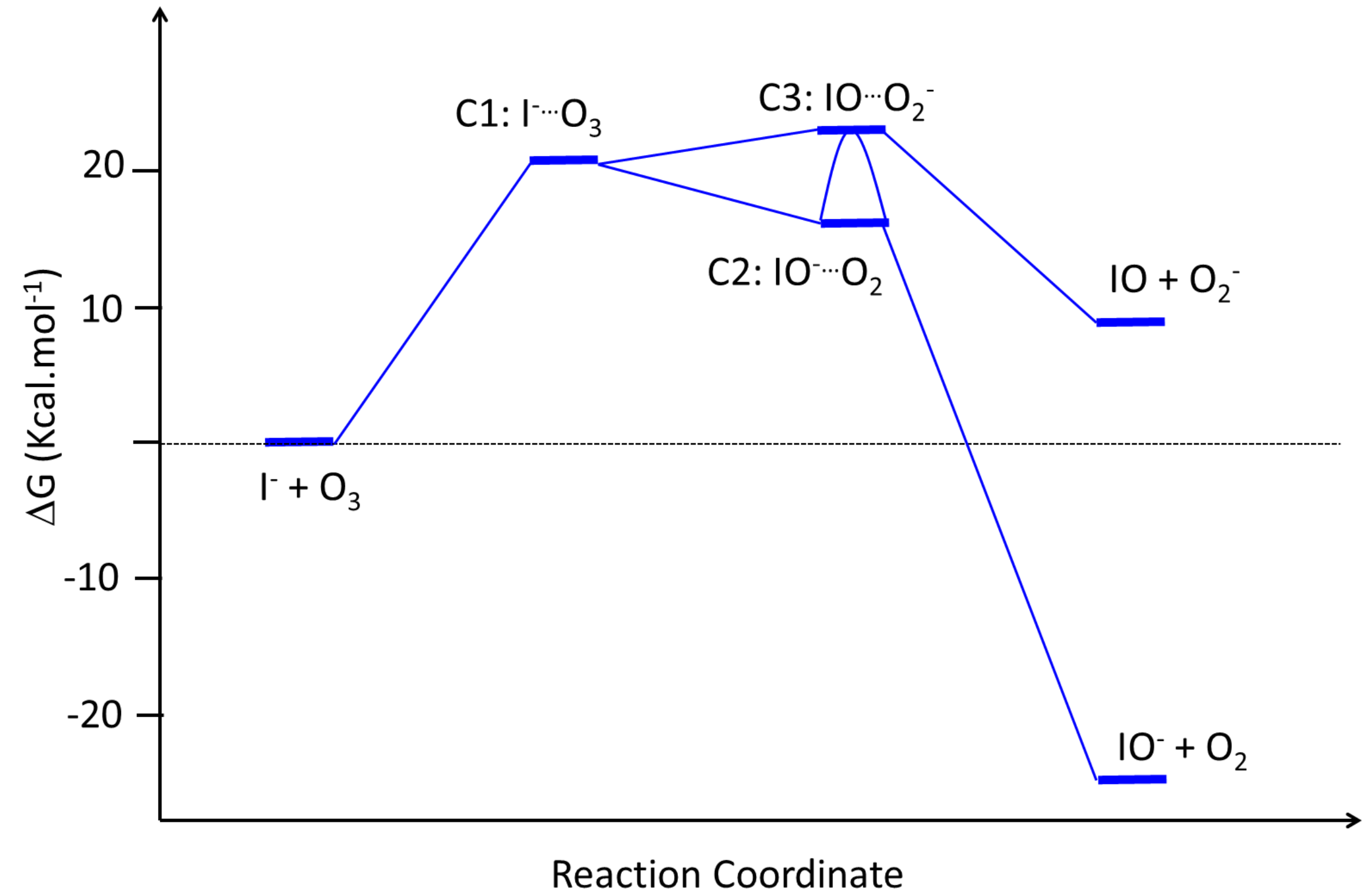

Figure 3. Reaction coordinate diagram for the variation of Gibbs free energy in the formation and destruction of $1000^{\circ}$ intermediate. $\Delta G$ values are calculated as described in Method section. 